\title{
THE EXCHANGE THEORY OF TEENAGE SMOKING AND THE COUNTERPRODUCTIVENESS OF MODERATE REGULATION
}

\author{
Kent Smetters \\ Jennifer Gravelle \\ Working Paper 8262 \\ http://www.nber.org/papers/w8262 \\ NATIONAL BUREAU OF ECONOMIC RESEARCH \\ 1050 Massachusetts Avenue \\ Cambridge, MA 02138 \\ April 2001
}

We are very grateful to Jane Gravelle for her numerous comments and insights. Neil Doherty also provided valuable comments. The views expressed herein are those of the authors and not necessarily those of the National Bureau of Economic Research.

(C) 2001 by Kent Smetters and Jennifer Gravelle. All rights reserved. Short sections of text, not to exceed two paragraphs, may be quoted without explicit permission provided that full credit, including (C) notice, is given to the source. 
The Exchange Theory of Teenage Smoking and the Counterproductiveness

of Moderate Regulation

Kent Smetters and Jennifer Gravelle

NBER Working Paper No. 8262

April 2001

JEL No. D11, L1, L2, L3, D62

\begin{abstract}
$\underline{\text { ABSTRACT }}$
About three-quarters of secondary schools are reluctant to vigorously enforce smoking bans due to various social pressures; ten percent of these schools do not have bans at all. Empirically, school-based smoking regulations appear, at best, ineffective at reducing teenage smoking and, more likely, may actually increase participation. Only schools which vigorously enforce bans have a lower smoking participation. In sum, teenage smoking participation appears to be non-monotonic in the level of enforcement. This paper develops an exchange model that explains this nonmonotonic pattern. Smoking bans provide an exchange opportunity to less popular students. Less popular students who begin smoking validate the risk-taking behavior of existing teenage smokers who, in exchange, provide friendship to the newcomers. The enforcement itself becomes the glue which holds the group together. Teenage smoking bans, unless vigorously enforced, increase teenage smoking participation. An increase in self-esteem and other non-smoking related qualities, however, undermines the trading channel, which can help combat teenage smoking. Numerous pieces of empirical evidence, culled from the empirical social psychology literature, are consistent with all of the key predictions of the model.
\end{abstract}

\author{
Kent Smetters \\ The Kaiser Visiting Professor \\ Stanford University (visiting 9/1/00 - 6/31/01) \\ Department of Economics \\ Stanford, CA 94305-6072 \\ \& \\ Assistant Professor \\ The Wharton School \\ University of Pennsylvania \\ 3641 Locust Walk, CPC 302 \\ Philadelphia, PA 19104-6218 \\ \& NBER \\ Tel: $215-898-9811$ \\ Fax: 215-898-0310 \\ Email: smetters@wharton.upenn.edu
}

\author{
Jennifer Gravelle \\ Ph.D. Candidate \\ Department of Economics \\ The Johns Hopkins University \\ 3400 N. Charles Street \\ Baltimore, MD 21218
}




\section{Background}

Smoking-related illness is the leading cause of preventable death in the United States and teenage smoking is especially important since most adult smokers began smoking as teenagers (Surgeon General's Report, 1994). The most common situation for first trying a cigarette is with a peer who already smokes (Ibid). Many schools during the past two decades, therefore, have tried to undermine the peer transmission mechanism with stronger enforcement of smoking bans on school grounds (Ibid; Portner, 1997).

Despite the increase in school smoking regulation, teenage smoking rose sharply during the 1990s. According to the University of Michigan's Monitoring the Future Project, the percentage of high school seniors who smoked one or more cigarettes per day in the previous thirty days rose from 17.2 in 1992, the lowest since 1976, to 24.6 in 1996 (CBO, 1998). Gruber (2000) shows that, although high school seniors are quite price sensitive, the decline in prices from 1992 to 1997 accounts for only about 30 percent of the increase in their participation. Moreover, younger teens appear to be fairly price insensitive. Hence, although prices are an important potential policy instrument to combat teenage smoking, their role appears to account for only a modest fraction of the total increase in youth smoking during the previous decade.

Rather than reducing smoking, school smoking regulations appear to be either ineffective (Charlton, et al, 1994; Pentz, et al, 1997; Gruber, 2000) or, in fact, have been associated with an increase in smoking participation. Wakefield, et al, (2000), in one of the most comprehensive surveys on teenage smoking, surveyed 17,287 high school students in 157 high schools on their smoking habits. They found that schools with smoking bans had a significantly larger share of students who are "established smokers" (smoked at least 100 cigarettes in their lifetime) than schools without smoking bans. This correlation is surprising since schools without smoking bans (8.2 
percent of all schools) are likely to be located in areas where smoking is more tolerated in general. Only schools which strongly enforced a smoking ban (28.3 percent of all schools) had significantly lower levels of smokers.

Pentz, et al, (1997) argues that school administrators often view tobacco use as less harmful than absence from school, or using other substances. School administrators have only moderately increased their efforts to combat teenage smoking in recent years, and most are reluctant to vigorously enforce anti-smoking regulations. Detentions (for first-time offenders) and suspensions (for repeat offenders) are common forms of punishment. This paper shows the peril of moderation. While vigorous enforcement can lead to a reduction in teenage smoking participation, moderate enforcement can actually increase it. Moderate enforcement provides an exchange opportunity that is non-existent under either zero enforcement (associated with a positive level of smoking) or under strict enforcement (associated with little smoking).

The Importance of Social Anchorage in the Decision to Smoke

A large literature in empirical social psychology has demonstrated a strong link between selfimage and social anchorage in a teenager's decision to smoke. Teenage smokers tend to have lower self-reported levels of self-esteem (Surgeon General's Report, 1994; Warheit, et al, 1995; Lifrak, et al, 1997; Glendinning and Inglis, 1999; Thorton, et al, 1999). Teenagers smoke, in large part, to become part of a social cluster, or a "smoke ring," in the words of Pearson and Lynn (2000): "risktaking peer clusters act as a greater focus of influence and selection of peripheral students at a key stage in their development than do non-risk-taking peer clusters.” (p. 21) A similar conclusion is found in Bell, et al, (1999).

Efforts to reduce teenage smoking can fail by not recognizing teenage smokers' motivations. Any theory that addresses the potential counterproductiveness of moderate high school smoking 
regulations must account for the previous empirical observations: 1) moderate enforcement of school smoking regulations either has no effect or actually increases teenage smoking, while strong enforcement reduces smoking; 2) smokers tend to have lower self-esteem; 3) peer groups have the greatest influence on smoking; 4) risk-taking peer groups are associated with smoking and, on average, have more peripheral members.

Enforcement itself might make the banned substance a desirable "forbidden fruit," as popularized by Milton and Rose Friedman (1981). However, the "forbidden fruit" view can be only part of a teenager smoker's motivation. First, the "forbidden fruit" theory does not distinguish between school and non-school smoking bans. Wakefield, et al, (2000) show that regulations in nonschool public places and at home are effective in reducing smoking; only moderate school-based regulations seem to be counterproductive. Second, the "forbidden fruit" theory does not alone account for the peer group and self-esteem factors discussed above. A teenage smoker's low selfidentity plays a key role in his or her decision to smoke, and smoking groups provide the acceptance they desire.

These observations suggest analyzing teenage smoking as an exchange. For an exchange to occur, new smokers must bring benefits to existing smokers. We argue that this benefit takes the form of risk reduction: new smokers reduce the subjective risks facing existing smokers in exchange for friendship.

\section{The Exchange Opportunity}

Social psychologists have demonstrated that peer groups enforce the message that a teenager who smokes is 'cool,' willing to break rules, and is part of the group, thereby validating the risk taking by other group members (Aloise and Hennigan, 1996; Young and Hennigan, 1996; Aloise, Hennigan and Graham, 1996; Amos, et al, 1997; Lloyd, et al, 1997; Lifrak, et al, 1997; Alexander, 
et al, 1999; Barber, et al, 1999; Falomir and Invernizzi, 1999). These observations suggest that group members subjectively see a reduction in the risk with new members through validation of the activity. As a result, teenage smokers are often defensively motivated when confronted with antitobacco efforts initiated by a higher non-familial authority (Falomir and Invernizzi, 1999). As enforcement increases, so does the "fox hole" type of bond. Anti-smoking efforts are the glue that holds them together. Only strong enforcement reduces teenage smoking participation.

What types of risks face teenagers? To be sure, teenagers are concerned about the health and addiction risks posed by smoking. Indeed, seventy percent of adolescent smokers wish they had never started smoking in the first place (CDC, 2001). However, while smokers in general are aware of the long-term health risks (Viscusi, 1990), teenage smokers, in particular, tend to underestimate the addictiveness of nicotine and overestimate their ability to quit. Of daily youth smokers who think that they will not smoke in five years, nearly 75 percent are still smoking in five years (CDC, 2001). To be sure, validation of the health-related risk taking associated with smoking is likely to play an important role in the group dynamics. Newcomers, for example, validate existing smoker's subjective belief in their future ability to quit. (Moreover, misery enjoys company.) But health and addiction is not the only risk teenager smokers face.

Another risk that teenager smokers face is the more immediate possibility of getting caught smoking by school authorities. The presence of new smokers reduces the probability of getting caught by enlarging the "herd" of smokers. To be sure, it may seem that smoking in a large group could increase the probability of getting caught by drawing attention. However, the nuances of school management suggests that the opposite is true. School authorities are quite sensitive to how their enforcement policies are perceived by students and parents (e.g., Pentz, et al, 1997). In practice, school administrators are reluctant to punish a large group of possible offenders that they 
catch smoking. A large number of suspensions suggests that the administrator cannot manage the school. Moreover, since the transgression is smoking rather than socializing with smokers, the administrator cannot plausibly punish the entire group since he cannot plausibly claim that he observed every member, or even a large number of members of the group, in the actual act of smoking. A mass punishment can also generate a concerted backlash from irate parents who might argue that their kid was falsely accused. Instead, school authorities are likely to pick someone who they definitely catch smoking and to punish them with detentions and (for repeat offenders) suspensions. A larger herd can also benefit smokers in more practical ways, including avoiding detection. Since smoking by just one person is a visible undertaking, a larger group allows smokers to take turns being "lookout" agents. The more smokers, the less time any smoker must spend at a distance from the group.

\section{Overview}

This paper develops an exchange model of teenage smoking participation. Newcomers offer existing smokers risk reduction in exchange for friendship. This risk reduction can take the form of reducing one another's concerns about the addiction and health risks claimed by authority figures, or reducing the more immediate chances of getting caught smoking. This risk reduction becomes more valuable in face of stronger smoking regulations by school officials. As a result, total smoking participation can increase in the level of the anti-smoking effort, even though the average smoking intensity may decrease due to the influx of less intensive smokers. Only tough and strongly enforced regulations reduce teenage smoking. The level of smoking participation is, therefore, non-monotonic in the level of enforcement.

Our model is related to the rational addiction literature (e.g., Becker and Murphy, 1988; Viscusi, 1990; Becker, Grossman, and Murphy, 1994; and Douglas, 1998). We show that usage of 
a harmful product can have a rational basis, but our focus is on social structure. While teenagers are often viewed by adults as irrational, research has supported rational reasons why teenagers smoke. For example, Wagner and Atkins (2000) find that the desire to control body weight is a motivation for why many teenage girls smoke. Thus, a model providing a rational reason for the increase in teenage smoking is not without its merits. Our model is also related to the literature on illegal drug use with supply responses to enforcement (e.g., Lee, 1993). However, our model addresses peer effects and, specifically, school-based smoking regulations, which are the bans that have been associated with the increase in teenage smoking.

\section{The Model}

Consider $N$ students in a given school. Teenager $j$ 's social status is derived from two sources: non-smoking related social qualities (i.e., social skills, etc.) and his/her smoking-related quality. The latter is a function of what the teenager is contributing to the group in the form of reducing their subjective risk taking. This quality is measured as the sum of the risk reduction to each of the other $N-1$ teenagers resulting from teenager $j$ 's level of smoking. (The reduction in risk to a non-smoker is zero which does not affect the sum.) Four variables enter positively in the utility function of teenager $j$ and each variable is discussed in more detail below: (1) agent $j$ 's subjective probability that something harmful will not happen to him or her if she smokes (e.g., poor future health or getting punished); (2) the sum of agent $j$ 's social status among non-smokers and among smokers; (3) agent $j$ 's smoking consumption; and (4) agent $j$ 's consumption of other goods:

$$
\begin{gathered}
u_{j}\left[1-p\left(e \cdot s_{j} /\left(1+\sum_{i \neq j}^{N} s_{i}\right)\right), \theta_{j}-\sum_{i \neq j}^{N} \Delta p_{j}^{i}, s_{j}, w_{j}-s_{j}\right] \\
s_{j} \geq 0
\end{gathered}
$$

where, 
- $\quad e$ is the non-negative level of anti-smoking effort by school authorities. The variable, $e$, reflects a combination of school regulations and the level of enforcement.

- $\quad s_{j}$ is the non-negative level of smoking by agent $j$ while $\sum_{i \neq j}^{N} s_{i}$ is the total level of smoking by other agents besides agent $j$.

- $\quad$ The function $p: \mathbb{R} \rightarrow[0,1]$ is a continuous measure of the subjective risk of smoking (health risk or the probability of getting caught). $p^{\prime}>0, p^{\prime \prime}<0, p(0)=0$ and $p(\infty)=1$.

- $\quad \theta_{j} \in \mathbb{R}_{+}$is the positive level of non-smoking related social qualities possessed by agent $j$.

- $\quad$ The operator $\Delta p_{j}{ }^{i}$ gives the change in the subjective risk of agent $i$ if agent $j$ also smokes:

$$
\Delta p_{j}^{i}=p\left(e \cdot s_{i} /\left(1+\sum_{j \neq i}^{N} s_{j}\right)\right)-p\left(e \cdot s_{i} /\left(1+\sum_{k \neq j \wedge k \neq i}^{N} s_{k}\right)\right) \leq 0
$$

Student $j$ 's smoking related quality equals what he or she is contributing to the group in the form of risk reduction, $-\sum_{i \neq j}^{N} \Delta p_{j}^{i}$.

- $\quad w_{j}$ is the non-negative level of financial resources this agent has (maybe from parents). So $\left(w_{j}-s_{j}\right)$ equals the consumption of non-smoking goods.

We make the following assumptions:

Assumptions Let $u_{j_{n}}$ denote the marginal utility of agent $j$ with respect to argument $n$. Second derivatives are denoted as $u_{j_{n n}}$. The function, $u_{j}(\cdot)$, is assumed to have the following partial derivatives:

(A1) $u_{j_{1}}>0, u_{j_{1}}(0, \cdot, \cdot)=\infty$.

(A2) $u_{j_{2}}>0, u_{j_{2}}(\cdot, 0, \cdot)=\infty$.

(A3) $\quad u_{j_{3}<}>, u_{j_{33}}<0, u_{j_{3}}(\cdot, \cdot, 0, \cdot)>-\infty$. 


$$
u_{j_{4}}>0, u_{j_{44}}<0, u_{j_{4}}(\cdot, \because, 0)=\infty, u_{j_{4}}(\cdot, \cdot, \infty)=0
$$

We now discuss equation (1) and assumptions (A1) - (A4).

\section{$\underline{\text { Discussion }}$}

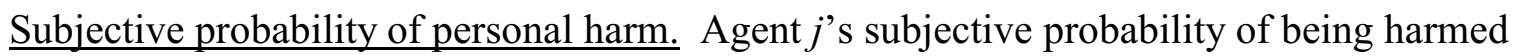
by smoking is a function of enforcement efforts, $e$, the agent's own smoking level, $s_{j}$, and the level of smoking by other agents, $\sum_{i \neq j} s_{i}$. These factors are expressed by the term $p\left(e \cdot s_{j} /\left(1+\sum_{i \neq j}^{N} s_{i}\right)\right)$ in equation (1).

A higher enforcement effort, $e$, increases agent $j$ 's subjective probability of tobacco-related harm, i.e., $p^{\prime}>0$. While information given by school authorities is not always trusted by teenagers, negative smoking publicity, ceteris paribus, is likely to increase teenager $j$ 's subjective risk of health-related sickness; more enforcement also directly increases his risk of getting caught.

A higher level of one's own smoking level, $s_{j}$, increases teenager $j$ 's subjective risk of harm. More smoking increases the chance of future health problems and, more immediately, increases the chance of getting punished by authorities. The terms $e$ and $s_{j}$ are multiplied together in the probability term, $p(\cdot)$, because a zero value for either $e$ or $s_{j}$ eliminates the subjective probability of harm (i.e., $e=0$ would imply no negative health-related information or enforcement).

An increase in the total level of smoking by other agents, $\sum_{i \neq j}^{N} s_{i}$, decreases the subjective probability of personal harm or directly decreases the probability of getting caught. A teenager smoker's beliefs and his or her willingness to act against authority is heavily influenced by the beliefs and actions of his or her peers. As discussed in Section I, teenage smokers like other teenage smokers. Every new smoker helps validate the subjective beliefs of existing smokers, lowering their subjective probability that something bad will happen to them in the future. Greater numbers provides reassurance that smoking is ok despite the negative information that kids hear about 
smoking. Greater numbers also help reduce the subjective fear of addiction and reduces the probability of getting caught smoking. Assumption(A1) reflects the following assumptions: a higher chance of not getting caught is desirable $\left(u_{j_{1}}>0\right)$ and someone will not smoke if they are guaranteed to get caught $\left(u_{j_{1}}(0, \cdot, \cdot)=\infty\right)$. This second assumption, however, is not strictly required.

Friendship. Friendship is assumed to increase in both the non-smoking related and smokingrelated social qualities that a person possesses: $\theta_{j}-\sum_{i \neq j}^{N} \Delta p_{j}{ }^{i}$. Recall that agent $j$ 's non-smoking related quality is $\theta_{j}$. Agent $j$ 's smoking-related quality is a function of what he or she is contributing to the group in the form of risk reduction: $-\sum_{i \neq j}^{N} \Delta p_{j}{ }^{i}$. This formulation assumes that a person's non-smoking and smoking-related qualities affects his level of friendships in an additively separable fashion. Hence, these qualities are neither substitutes (i.e., non-smoking students do not disdain smokers) nor complements (i.e., non-smoking students do not admire smokers). Allowing for complements would enhance our results. We could also allow for some substitutes. To be sure, if the non-smoking and smoking-related qualities were substitutes, it would decrease the likelihood that a non-smoker begins smoking upon stricter anti-tobacco enforcement. However, students most likely to increase their smoking after an increase in enforcement are those who already have low values of $\boldsymbol{\theta}$, the non-smoking related quality, and therefore have little to lose. Assumption (A2) implies that greater friendships are always desirable $\left(u_{j_{2}}>0\right)$ and no friendships at all is highly undesirable $\left(u_{j_{2}}(\cdot, 0, \cdot)=\infty\right)$. This second assumption is a reasonable assumption for most young people but our model could be enhanced to allow for some hermits.

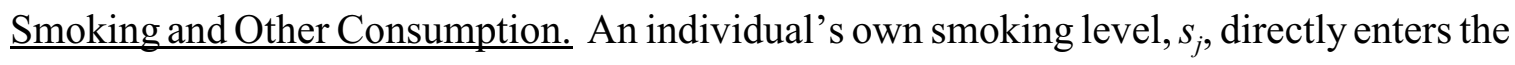
utility function. As shown in assumption (A3), we place no conditions on whether a given person likes or dislikes smoking $\left(u_{j_{3}}<0\right)$. Some reasons why teenagers smoke include an intrinsic pleasure, weight control, and stress relief. Others might dislike smoking because of taste. The 
marginal utility of additional tobacco use (possibly negative), though, decreases with an increase in smoking $\left(u_{j_{33}}<0\right)$. Moreover, no person dislikes smoking so much they would be willing to forfeit all of their non-smoking consumption or friendships to avoid just one "drag" of cigarette smoke $\left(u_{j_{3}}(\cdot, \cdot, 0, \cdot)>-\infty\right)$. This last assumption, while simplifying the analysis, is not strictly required. All we require is that, under zero enforcement, the numbers of smokers and non-smokers are nonzero, i.e.,

There exists at least one agent $j$ and one agent $k$ such that $u_{j_{3}}\left(0, \theta_{j}, 0, w_{j}\right)>u_{j_{4}}\left(0, \theta_{j}, 0, w_{j}\right)$ and $u_{k_{3}}\left(0, \theta_{k}, 0, w_{k}\right)<u_{k_{4}}\left(0, \theta_{k}, 0, w_{k}\right)$.

The specification for non-smoking consumption, $w_{j}-s_{j}$, is standard: more is better $\left(u_{j_{4}}>0\right)$ with decreasing returns $\left(u_{j_{44}}<0\right)$; zero consumption is very costly $\left(u_{j_{4}}(\cdot, \because, 0)=\infty\right)$; agents are satiated only in the limit $\left(u_{j_{4}}(\because, ;, \infty)=0\right)$.

\section{Equilibrium}

Define $s_{j}^{*}$ as the optimal solution to equation (1):

$$
s_{j}^{*}=\underset{s_{j}}{\operatorname{argmax}} u_{j}(\cdot, \cdot, \cdot, \cdot)
$$

We call agent $j$ a smoker if $s_{j}^{*}>0$.

Let $\underline{\theta}=<\theta_{1}, \theta_{2}, \cdots, \theta_{\mathrm{N}}>$ be the vector of non-smoking related qualities across all agents and let $\Theta=\left\{\underline{\theta} \times \underline{\theta} \mid \underline{\theta} \in \mathbb{R}_{+}^{N}\right\}$ be the set of all possible vectors. By the implicit function theorem, there exists functions, $f_{j}$, such that,

$$
s_{j}^{*}=f_{j}\left(e, \sum_{i \neq j}^{N} s_{i}^{*}\right) \quad, \quad 1 \leq j \leq \mathrm{N}
$$


Equation (4) says that agent $j$ 's level of smoking is a function of the level of anti-tobacco enforcement, and (when enforcement is positive) the level of smoking of other agents. It gives a system of demand equations that must be solved for simultaneously when $e>0$. In general, the value of $s_{j}{ }^{*}$ is independent of the value of $s_{i}{ }^{*}(i \neq j)$ only when $e=0$. This leads to the following definition,

Definition An equilibrium is the vector $\left\langle s_{1}{ }^{*}, s_{2}{ }^{*}, \cdots, s_{N}^{*}>\right.$ that simultaneously solves the set of equations, (4), for given values of $e$ and $\underline{\theta}$.

\section{Theoretical Results}

This section states several theorems, proven in Appendix A, that demonstrate the potential counter-productivity of a marginal increase in smoking restrictions. An illustrative numerical example is presented in Appendix B. Our first result simply reflects the fact that with zero enforcement, the optimization problem faced by agents is standard.

Theorem 1 At zero enforcement $(e=0)$, an equilibrium exists and it is unique.

Our second result shows that an increase in enforcement $(e)$ can lead to an increase in smoking participation. On one hand, an increase in $e$ increases the subjective probability of harm, thereby, reducing smoking. On the other hand, an increase in $e$ increases the potential for an agent with a lower value of $\theta$ to increase his or her social acceptance by smoking in order to exchange the service of risk reduction for friendship. The exact value of $\underline{\theta}$ determines the outcome, as now formally stated:

Theorem 2 For any utility function satisfying assumption (A1) - (A5), there exists a value of e > 
0 and a non-empty subset $\Theta_{I} \subset \Theta$ such that for each $\underline{\theta} \in \Theta_{I}$, the total number of smokers is larger relative to zero enforcement $(e=0)$.

It is important to note, however, what Theorem 2 does not say. It focuses only on the total number of smokers and says nothing about the average intensity. Whether the average intensity increases or decreases depends, in part, on the relative differences in financial resources between smokers and non-smokers and on differences in preferences. When, however, agents share the same resources and preferences, smoking intensity generally declines after an increase in enforcement as less intense smokers are added to the pool. But many people concerned about teenage smoking focus on participation since it is well established that most smokers were introduced to smoking as teenagers (Section I).

Our next result shows that a large enough level of enforcement, however, will reduce the level of smoking below that under zero enforcement.

Theorem 3 For a given value of $\underline{\theta}$, there exists a level of enforcement, $\hat{e}$, such that $\forall e>\hat{e}$ the number of smokers will be lower than under no enforcement.

Our final result shows that an across-the-board increase in social skills can lead to lower smoking participation. Schools that foster greater interaction among their students, therefore, can possibly enjoy a lower level of smoking participation.

Theorem 4 For a given value of $\underline{\theta}$ and $e>0$ (given by Theorem 2), there exists a vector $\underline{\hat{\theta}}>\underline{\theta}$

$$
\text { (i.e., } \hat{\theta}_{j} \geq \theta_{j} \forall j \text { ) such that the equilibrium number of smokers is lower. }
$$

\section{Discussion}

Despite more restrictive school smoking policies, teenage smoking has risen (Section I). The 
model herein predicts that it is possible that the increase in restrictions could have been a contributing factor. Some evidence suggests that schools with higher smoking restrictions tend to have both a higher smoking participation and a lower average cigarette consumption per smoker. ${ }^{1}$ This empirical relationship is consistent with our model: greater enforcement provides an opportunity for less popular students to make friends, but the influx of less intensive smokers reduces average tobacco consumption. The fact that teenage smokers, on average, self-report lower levels of self-esteem and self-assessed worth to others (Section I) also suggests that this exchange mechanism might be very operative. Indeed, the model predicts that, for students $j$ and $k$ with identical utility functions and resources, student $j$ smokes more than student $k$ iff student $j$ has lower social qualities, i.e., $s_{j}^{*}>s_{k}^{*} \Leftrightarrow \theta_{j}-\sum_{i \neq j}^{N} \Delta p_{j}{ }^{i}<\theta_{k}-\sum_{i \neq j}^{N} \Delta p_{k}{ }^{i}$.

Several effective ways to reduce teenage smoking are consistent with the model herein. First, reducing enforcement might lead to lower participation. But the level of smoking under no enforcement might still be unacceptably high. Second, schools can increase enforcement levels to very high levels. But this approach might be costly or may be deemed inappropriate if draconian measures of enforcement are required (i.e., the value of $\hat{e}$ is very high). See, e.g., Pentz, et al (1997). Third, schools can attempt to increase non-smoking social qualities by directly focusing on a child's self-esteem. The Life Skills Program (Botvin, et al, 2000), that is now being employed in many schools across the United States, takes this approach. Another program, the Hutchinson Smoking Prevention Project, however, has been criticized recently as being less effective over a longer-term period (Peterson, et al, 2000). The Hutchinson project attempts to use peer pressure to reduce smoking, rather focusing directly on self-esteem variables.

\footnotetext{
${ }^{1}$ The positive relationship between participation and school bans is shown in Wakefield (2000), as discussed in Section I. Chaloupka and Grossman (1996) don't find a significant effect of tighter school bans on participation (their positive sign was significant only the 80 percent confidence level). However, they did find a significant negative effect between the average cigarette consumption and increased smoking restrictions (at the $99 \%$ level).
} 


\section{Conclusions}

This paper presented an model of exchange which might help explain the recent increase in teenage smoking despite a moderate increase in enforcement of teenage smoking bans at many schools nationwide. An increase in enforcement might encourage less-popular students to smoke in order to increase their social acceptance. These new smokers reduce existing smoker's probability of harm in exchange for friendship. This exchange opportunity becomes more valuable at higher levels of enforcement, and enforcement efforts themselves become the glue which bond teenage smoking groups together. Empirical evidence is consistent with the key elements of model. Teenage smokers tend to hold lower self-esteem, and the role of peers plays a critical role in their decision to smoke. School smoking bans are associated with both a higher level of participation but a lower level of average consumption. A combination of very strong enforcement (if appropriate) and programs that focus on life skills and social development are more effective. 


\section{Appendix A: Proofs}

Theorem 1 The programming problem for agent $j$ under zero enforcement equals,

$$
u_{j}\left\lfloor 1, \theta_{j}, s_{j}, w_{j}-s_{j}\right\rfloor
$$

where the first two parameters are exogenous. Since no restrictions are placed on the sign of $u_{j_{3}}$, we must consider two cases. Case 1: Suppose $u_{j_{3}}\left(1, \theta_{j}, 0, w\right)<u_{j_{4}}\left(1, \theta_{j}, 0, w\right)$. Then $s_{j}{ }^{*}=0$ and $c_{j}^{*}=w_{j}$ is the unique solution. Case 2: Suppose $u_{j_{3}}\left(1, \theta_{j}, 0, w\right)>u_{j_{4}}\left(1, \theta_{j}, 0, w\right)$. Then $s_{j}^{*}>0$ and $c_{j}^{*}<w_{j}$, and $c_{j}^{*}>0$ since $u_{j_{4}}(\cdot, \cdot, 0)=\infty$. This solution is unique since $u_{j_{33}}<0$ and $u_{j_{44}}<0$.

Theorem 2 We first prove that there exists a value of $e>0$ such that $\Theta_{\mathrm{I}}$, as defined in Theorem 2 , is non-empty. By assumption (A5), there exists at least one agent $j$ such that $\mathrm{u}_{j_{3}}(0, \cdot, 0, w)>$ $\mathrm{u}_{j_{4}}(0, \cdot, 0, w)$, i.e., they will want to smoke under zero enforcement. Hence, there is a value of $e>0$ such that agent $j$ is willing to continue smoking even if no other agent smokes, i.e., $\left.\left.u_{j_{3}} \mid 1-p\left(e \cdot s_{j}\right), \theta_{j}, 0, w_{j}\right\rfloor>u_{j_{4}} \mid 1-p\left(e \cdot s_{j}\right), \theta_{j}, 0, w_{j}\right\rfloor$. For this value of $e$, there is a $\xi_{i}>0$ such that for $\forall \theta_{i}<\xi_{\text {, }}$ agent $i$ smokes since $\left.\left.\left.u_{i_{2}} \mid 1,0,0, w_{i}\right\rfloor>\left|u_{i_{3}\lfloor}\right| 1,0,0, w_{i}\right\rfloor\left|u_{i_{2}\lfloor}\right| 1,0,0, w_{i}\right\rfloor>u_{i_{4}}\left\lfloor 1,0,0, w_{i}\right\rfloor$, and $u_{i_{2}}\left\lfloor 1,0,0, w_{i}\right\rfloor$ $=\infty>\lim u_{i_{1}}\left|x, 0,0, w_{i}\right|$ even if agent $j$ is the only other smoker. Hence, $<\xi_{1}, \xi_{2}, \ldots, \xi_{j-1}, \theta_{\mathrm{j}}, \xi_{j+1}, \ldots$, $x \uparrow 1$ $\xi_{N}>\in \Theta_{\mathrm{I}}$ and so $\Theta_{\mathrm{I}}$ is non-empty.

Theorem 3 This result follows directly from the assumption $u_{j_{1}}(0, \because, \cdot)=\infty$. Theorem 4 Obvious. Follows from the proof to Theorem 2. 


\section{Appendix B: Illustrative Numerical Example}

Consider the following functional form for the utility function:

$$
\begin{gathered}
u_{j}\left[a, b, s_{j}, w_{j}-s_{j}\right]=a_{j}^{1 / 2}+b_{j}^{1 / 2}+\left(0.1+s_{j}\right)^{\alpha_{j}}+\left(w_{j}-c_{j}\right)^{1 / 2} \\
a_{j} \equiv 1-p\left(e \cdot s_{j} /\left(1+\sum_{i \neq j}^{N} s_{j}\right)\right) \\
b_{j} \equiv \theta_{j}-\sum_{i \neq j}^{N} \Delta p_{j}^{i}
\end{gathered}
$$

The presence of 0.1 in the third term of $u_{j}\left[{ }^{[}\right]$allows $s_{j}=0$ (no smoking) to be a possible outcome. The probability of getting caught or subjective risk is assumed to be given by the continuous function

$$
p(x)=1-\frac{1}{(1+x)^{1 / 2}}
$$

Consider $N=3$ agents with the following social skills and preference parameters. For agent $1,<\theta_{1}, \alpha_{1}>=<0,0>$; for agent $2,<\theta_{2}, \alpha_{2}>=<0.1,0.2>$; and for agent $3,<\theta_{3}, \alpha_{3}>=<0.2,0.1$ >. In words, the agent with the most appetite to smoke, agent 2, is the one with the middle value of social skills. Also normalize $w_{j}=10 \forall j$.

For $e=0$ (no enforcement), the optimal level of smoking for each agent, $s_{j}^{*}$, is easy to compute since there are no smoking externalities. The solutions are $s_{1}{ }^{*}=0, s_{2}{ }^{*}=1.14$, and $s_{3}{ }^{*}=$ 0.48. In words, agent 1 spends zero percent of her resources on smoking, agent 2 spends 11 percent and agent 3 spends 5 percent.

Increasing $e$ to 3.0 requires simultaneously solving a small set of demand functions like 
equation set (4) due to the presence of a smoking externality. ${ }^{2}$ The equilibrium solutions are: $s_{1}{ }^{*}=$ $0.15, s_{2}{ }^{*}=0.72$, and $s_{3}{ }^{*}=0.18$. The increase in enforcement has increased the level of smoking participation, although the average intensity has decreased. Agent 1 begins smoking even though she does not enjoy it per se. The restriction also shifts the pool of smokers toward those with lower social skills.

Increasing the value of $e$ to 5.0, however, leads to zero smoking by all agents.

If instead, the level of $e$ stays at 3.0 and we increase the popularity of agent 1 from $\theta_{1}=0$ to 0.2 , the new equilibrium smoking values become $s_{1}{ }^{*}=0.0, s_{2}{ }^{*}=0.24$, and $s_{3}{ }^{*}=0.05$. Agent 1 stops smoking because she is now already popular enough: she would now rather spend her money on non-smoking consumption since she does not enjoy smoking. This leads to an increase in the probability that agent 2 and 3 get caught smoking which reduces their level of smoking.

\footnotetext{
${ }^{2}$ Note that this externality, however, is pecuniary with the price given by the probability $p$.
} 


\section{References}

Alexander, Cheryl, Peg Allen, Myra Crawford, and Laura McCormick. "Taking a First Puff: Cigarette Smoking Experiences Among Ethnically Diverse Adolescents." Ethnicity and Health, 4 (4), November 1999: 245 - 257.

Aloise-Young, Patricia and Karen Hennigan. "Self-Image, the Smoker Sterotype and Cigarette Smoking: Development Patterns from Fifth Through Eighth Grade." Journal of Adolescence, 19 (2), April 1996: 163 - 177.

Aloise-Young, Patricia and Karen Hennigan, and John Graham. "Role of the Self-Image and Smoker Stereotype in Smoking Onset During Early Adolescence: A Longitudinal Study." Health Psychology, 15 (6), November 1996: 494 - 497.

Amos, Amanda, David Gray, Candace Currie and Rob Elton. "Healthy or Druggy? Self-Image, Ideal Image, and Smoking Behaviour Among Young People." Social Science \& Medicine, 45 (6), Sep 1997: 847 - 858 .

Barber, James, Floyd Bolitho and Lorne Bertrand. "The Predictors of Adolescent Smoking." Journal of Social Service Research, 26 (1), 1999: 51 - 66.

Becker, Gary and Kevin Murphy. "A Theory of Rational Addiction.” Journal of Political Economy, 94 (4): 675-700, August, 1988.

Becker, Gary, Michael Grossman, and Kevin Murphy. "An Empirical Analysis of Cigarette Addiction." American Economic Review, 84 (3): 396-418, June, 1994.

Bell, Robert, Stephen Pavis, Amanda Amos, and Sarah Cunningham-Burley, "Continuities and Changes: Teenage smoking and occupational transition." Journal of Adolescence, Oct 1999, 22 (5): 683-694.

Center for Disease Control. "Incidence of Initiation of Cigarette Smoking Among U.S. Teens." (Available at http://www.cdc.gov/tobacco/research_data/youth/initfact.htm).

Chaloupka, Frank J. and Michael Grossman. "Price, Tobacco Control, and Youth Smoking." National Bureau of Economic Research Working Paper 5740. September, 1996.

Crisp, Arthur, Philip Sedgwick, Christine Halek, Neil Joughin, Humphrey Heather. "Why May Teenage Girls Persist in Smoking?” Journal of Adolescence, Oct 1999, 22(5): 657-672.

Douglas, Stratford. "The Duration of the Smoking Habit." Economic Inquiry, 36 (1): 49-64, January, 1998.

Falomir, Juan and Federica Invernizzi. "The Role of Social Influence and Smoker Identity in Resistance to Smoking Cessation.” Swiss Journal of Psychology, 58 (3), June 1999: 73 - 84.

Friedman, Milton and Rose Friedman. Free to Choose: A Personal Statement., Avon Books: New York, NY, 1981. 
Glendinning, Anthony and David Inglis. "Smoking Behaviour in Youth: The Problem of Low SelfEsteem?" Journal of Adolescence, 22 (5), October 1999, 673 - 682.

Isohanni, Matti, Irma Moilanen, Paula Rantakallio. "Determinants of Teenage Smoking, with Special Reference to Non-standard Family Background." British Journal of Addiction, 1991, 86 (4): 391-398.

Lifrak, Partricia, James McKay, Anthony Rostain, Arthur Alterman, et al. "Relationship of Perceived Competencies, Perceived Social Support, and Gender to Substance Use in Young Adolescents." Journal of the American Academy of Child \& Adolescent Psychiatry, 36 (7), July 1997: 933 - 940.

Lee, Li Way. “Would Harassing Drug Users Work?” Journal of Political Economy, (101), 5, 1993 : 939 - 959.

Lloyd, Barbara, Kevin Lucas, and Madeline Fernbach. "Adolescent Girls' Constructions of Smoking Identities: Implications for Health Promotion.” Journal of Adolescence, 20 (1), February 1997: 4356.

Pearson, Michael and Lynn Michell. "Smoke Rings: Social Network Analysis of Friendship Groups, Smoking and Drug-Taking." Drugs: Education, Prevention and Policy, 7 (1), February 2000: 21 37.

Pentz, MA, S. Sussman and T. Newman. "The Conflict Between Least Harm and No-Use Tobacco Policy for Youth: Ethical and Policy Implications.” Addiction 1997, 92 (9): 1165 - 1173.

Peterson, Arthur V., Jr., Kathleen A. Kealey, Sue L. Mann, Patrick M. Marek, and Irwin G. Sarason. "Hutchinson Smoking Prevention Project: Long-Term Randomized Trial in School-Based Tobacco Use Prevention. Results on Smoking." Journal of the National Cancer Institute, 2000, 92, 24.

Portner, Jessica. "Despite Heat on Tobacco Producers, Some Schools Still Permit Smoking." Education Week on the Web, October 29, 1997.

Thorton, William, Graham Douglas, and Stephen Houghton. "Transition through Stages of Smoking: The Effect of Gender and Self-Concept on Adolescent Smoking Behavior." Journal of Adolescent Health, 25 (4), October 1999: 284 - 289.

U. S. Congressional Budget Office. The Proposed Tobacco Settlement: Issues From a Federal Perspective. CBO Paper, Washington, D.C., April, 1998.

U. S. Department of Health and Human Services, Preventing Tobacco Use Among Young People: A Report of the Surgeon General. Atlanta, Georgia: U.S, Department of Health and Human Services, Public Health Service, Centers for Disease Control and Prevention, National Center for Chronic Disease Prevention and Health Promotion, Office on Smoking and Health, 1994.

Viscusi, W. Kip. "Do Smokers Underestimate Risks?” Journal of Political Economy, December, 1990, 98 (6): 1253-69. 
Wagner, Eric F. and Jana H. Atkins, "Smoking among teenage girls." Journal of Child \& Adolescent Substance Abuse, 2000, 9 (4): 93-110.

Warheit, George, Frank Biafora, Rick Zimmerman, and Gil Andres. "Self-rejection / derogation, Peer Factors, and Alcohol, Drug and Cigarette Use Among a Sample of Hispanic, African-American, and White non-Hispanic Adolescents." International Journal of the Addictions, 30 (2), January, 1995: 97 - 116. 